\title{
Reply to a letter to the Editor regarding the article "Blood pressure and hypertension in people living at high altitude in Nepal"
}

\author{
Nirmal Aryal ${ }^{1} \cdot$ Mark Weatherall $^{2} \cdot$ Yadav Kumar Deo Bhatta ${ }^{3} \cdot$ Stewart Mann $^{2}$
}

Received: 5 January 2019 / Accepted: 8 January 2019 / Published online: 1 April 2019

(c) The Japanese Society of Hypertension 2019

Dear Editor-in-Chief,

We would like to thank Martin and Johannes for their pertinent concern about omitting temperature from our multivariate model. We agree that, as they suggested, the inclusion of temperature would have definitely added value to this research had we collected data on ambient temperature during each blood pressure measurement. However, we previously acknowledged that possible temperature differences in study districts might have modified the effect of altitude on blood pressure.

As described in the methods section, data were collected during the summer in the Mustang district (average ambient temperature $25^{\circ} \mathrm{C}$ to $31^{\circ} \mathrm{C}$ ) and during spring in the Humla district (average ambient temperature $\sim 15^{\circ} \mathrm{C}$ ). A recent systematic review by Wang and colleagues estimated that a $1{ }^{\circ} \mathrm{C}$ decrease in mean daily ambient temperature was associated with increases in systolic blood pressure and diastolic blood pressure of 0.26 and $0.13 \mathrm{mmHg}$, respectively [1]. According to this estimate, the difference in temperature in the two study districts alone could affect SBP by $2.6-4.2 \mathrm{mmHg}$ and DBP by $1.3-2.1 \mathrm{mmHg}$. However, since blood pressure measurements were carried out indoors, this effect should have been less substantial.

\section{Compliance with ethical standards}

Conflict of interest The authors declare that they have no conflict of interest.

Publisher's note: Springer Nature remains neutral with regard to jurisdictional claims in published maps and institutional affiliations.

\section{References}

1. Wang Q, Li C, Guo Y, Barnett AG, Tong S, Phung D, et al. Environmental ambient temperature and blood pressure in adults: A systematic review and meta-analysis. Sci Total Environ. 2017;575:276-86.
Nirmal Aryal

naryal@bournemouth.ac.uk

1 Faculty of Health and Social Sciences, Bournemouth University, Bournemouth BH1 3LT, UK

2 Department of Medicine, University of Otago, Wellington, New Zealand

3 Department of Cardiology, Norvic International Hospital, Kathmandu, Nepal 